\title{
Sonographic appearance of rhabdomyolysis - a systematic review of the literature
}

\author{
Lukasz Sein Anand, Wojciech Kosiak
}

Laboratory of Diagnostic Ultrasound and Biopsy, Department of Pediatrics, Oncology, Hematology and Endocrinology, University Clinical Center in Gdańsk, Gdańsk, Poland

\begin{abstract}
Rhabdomyolysis is the process of striated muscle cell lysis, during which proteins and microelements such as myoglobin are released into the bloodstream. It is important to diagnose rhabdomyolysis as soon as possible and start the treatment according to severity, as it is a state that significantly increases the mortality of the patients. The current gold standard of rhabdomyolysis diagnosis is the creatine kinase plasma concentration test, but it can be also diagnosed with imaging techniques, such as ultrasound (US). This review aims to gather previously published information regarding sonographic appearance of rhabdomyolysis. We searched through PubMed and ScienceDirect databases for studies using designed queries. After the selection process we were left with 13 studies containing a description of US appearance of rhabdomyolysis confirmed with a CK plasma level test. Findings described in the majority of the cases were muscle thickening, ground glass opacity, traits of edema and anechoic areas. Other than these, there were several less often reported findings. As a conclusion, rhabdomyolysis seems to have its own US appearance, but for now it cannot be precisely specified and needs further research for clarification.

Keywords: ultrasonography; rhabdomyolysis; point-of-care
\end{abstract}

\section{Introduction}

Rhabdomyolysis is the process of striated muscle cells lysis, during which proteins and microelements such as creatine kinase (CK), myoglobin and potassium ions are released into the bloodstream [1]. An estimation of the statistics of rhabdomyolysis occurrence is at the moment difficult, as it is frequently oligosymptomatic or asymptomatic [2], and thus may be unnoticed by the physician. Among the most frequently reported causes of

Received 30.10.2019 Accepted 12.12.2019

Med Ultrason

2020, Vol. 22, No 1, 92-96

Corresponding author: Łukasz Sein Anand

Laboratory of Diagnostic Ultrasound and

Biopsy, Department of Pediatrics, Oncology,

Hematology and Endocrinology,

University Clinical Center in Gdańsk,

7 Dębinki street, 80-952, Gdańsk, Poland

E-mail: 1sanand@gumed.edu.pl rhabdomyolysis are the use of narcotics and drug abuse (most of which are stimulants such as amphetamine and cocaine), trauma and seizures [1]. Rhabdomyolysis presents mostly as flu-like symptoms and sharp muscle pain accompanied by redness, soreness and tenderness around the muscle area. The most distinctive symptom for striated muscle lysis is myoglobinuria caused by excretion of myoglobin through the kidneys, appearing as dark brown urine, described often as tea-colored or cola-colored, but, because of the relatively quick renal clearance of myoglobin, it often lasts for only short amount of time, and may be overlooked by both patients and physicians [1].

During excretion of myoglobin, renal function can be impaired in three different mechanisms: 1) mechanical occlusion of renal tubules; 2) direct toxicity of myoglobin towards renal tubules [3]; and 3) enhancement of afferent arterioles contractile response to angiotensin II, thus effectively lowering renal perfusion [4]. Due to these pathways, patients with rhabdomyolysis have an 
increased risk for acute kidney injury (AKI), a condition that substantially increases morbidity [5]. Moreover, potassium ions released to the bloodstream alongside myoglobin may elevate the serum level and thus be a potential cause for deadly heart arrythmias [6].

Because of the morbidity risk of rhabdomyolysis complications, a rapid diagnosis and treatment introduction is crucial, based mostly on aggressive fluid therapy, or in more severe cases of AKI based on continuous renal replacement therapy (CRRT) [7]. The current gold standard of rhabdomyolysis diagnosis is the measurement of CK plasma concentration. Concentration level exceeding $1,000 \mathrm{U} / 1$, which represents value exceeding the upper limit of the normal range multiplied by 5 is considered a cut-off value for striated muscle lysis [3]. Imaging methods, such as computed tomography (CT), magnetic resonance imaging (MRI), scintigraphy and ultrasound (US) are also used in the diagnosis of rhabdomyolysis, allowing the accurate localization and measurement of the injury size and in some cases early or even accidental diagnosis of rhabdomyolysis [8]. The first published US paper about rhabdomyolysis was a case of a 28 -year-old woman with rhabdomyolysis confirmed through a CK plasma concentration test. During his examination, Kaplan described an US image of the thigh area, containing a focal hypoechoic lesion inside a muscle, which was consistent with findings found in both MRI and scintigraphy in the same area [9]. Since then, new studies and publications regarding ultrasound in rhabdomyolysis diagnosis have started to appear, in which appearance of more than 80 cases of striated muscle lysis have been described [9-20].

This review gathers and presents previously published information on the US appearance of rhabdomyolysis, as a basis for further original research on the subject.

\section{Materials and methods}

Using different combination of keywords related to US and rhabdomyolysis, we designed a query for PubMed and ScienceDirect databases. For PubMed we used ("Rhabdomyolysis" OR "Rhabdomyolyses" OR "Myoglobinuria") AND ("Ultrasound" OR "Sonography" OR "Sonographic" OR "Ultrasonography" OR "Ultrasonic"), which gave us 96 entries. For ScienceDirect we used (Rhabdomyolysis OR Rhabdomyolyses OR Myoglobinuria) AND (Ultrasound OR Sonography OR Sonographic OR Ultrasonography OR Ultrasonic) in "Title, abstract or author-specified keywords" input box, which gave us 15 entries. From 101 records that were left after removing duplicates, 48 records which addressed the topic of rhabdomyolysis were examined. From these, 35 publications were excluded for not containing a descrip-

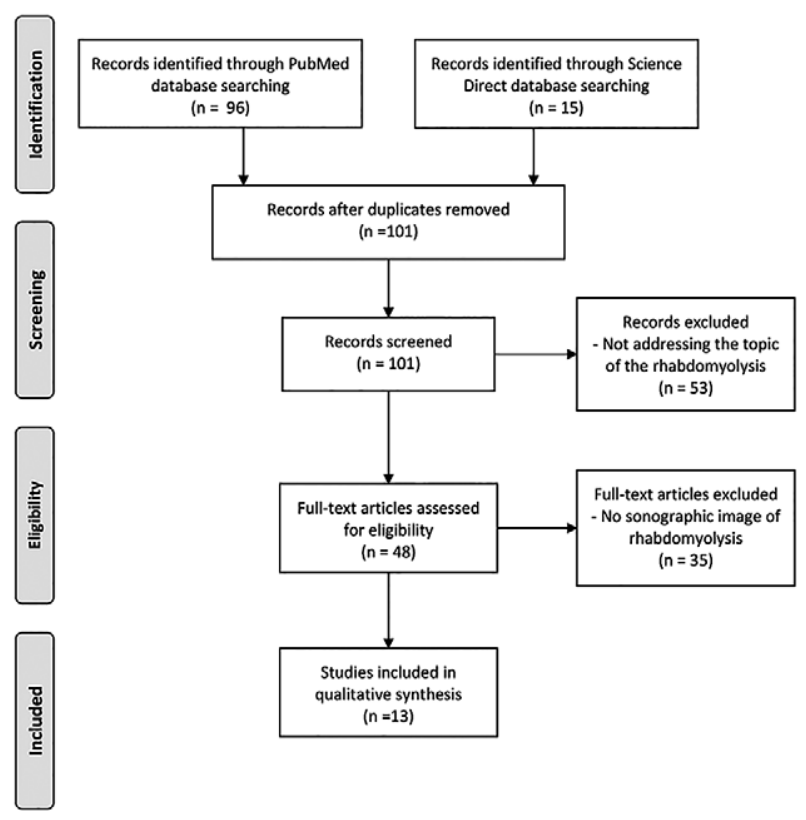

Fig 1. Flow chart of the publications' selection process

tion of sonographic image of rhabdomyolysis acquired by the authors, leaving us with 13 papers included in our review. The selection process is presented on a flow diagram (fig 1). Those 13 included publications were then analyzed, using four key-points as a basis of analysis: 1) ultrasound device, transducer and frequency used during examination; 2) number of cases presented; 3 ) described findings in US muscle appearance; and 4) CK plasma concentration or CK concentration range in case of more than one case. Data gathered during full-text analysis was then presented in Table I. The findings were then gathered and put together in a form of an additional table, with separate results for all published papers and for papers published in the years 2008 to 2017 (Table II).

\section{Results}

The most frequent pathological findings described in the analyzed publications were hypoechoic lesion/s $(70 \%$ of all publications) and heterogeneous echogenicity (54\% of all publications). Despite being described in the majority of studies, they were seen only in the minority of all cases (15\% and $13 \%$, respectively). Looking exclusively at the studies published between 2008 and $2017,50 \%$ of the papers contained findings of thickening of the muscle and ground glass opacity, which were also present in the majority of published cases $(87 \%$ and $85 \%$, respectively). Moreover, in the majority of the cases, traits of edema $(68 \%)$ and presence of anechoic areas $(61 \%)$ were described. In $9 \%$ of all described cases there were no 
Table I. Basic information found during full-text analysis

\begin{tabular}{|c|c|c|c|c|c|c|}
\hline $\begin{array}{l}\text { Author, year of } \\
\text { publication }\end{array}$ & Device & $\begin{array}{l}\text { Trans- } \\
\text { ducer }\end{array}$ & $\begin{array}{l}\text { Transducer } \\
\text { frequency }\end{array}$ & $\mathbf{N}$ & Ultrasound findings* & CK \\
\hline Kaplan 1980 [9] & NI & NI & NI & 1 & Hypoechoic lesion & $12280 \mathrm{U} / 1$ \\
\hline $\begin{array}{l}\text { Fornage } \\
1986[10]\end{array}$ & $\begin{array}{l}\text { Toshiba } \\
\text { SAL-30A }\end{array}$ & NI & 3.5-5 MHz & 1 & $\begin{array}{l}\text { Hypoechoic lesion } \\
\text { Hyperechoic intercalation inside } \\
\text { hypoechoic lesion }\end{array}$ & NI \\
\hline $\begin{array}{l}\text { Lamminen } \\
1989 \text { [11] }\end{array}$ & $\begin{array}{l}\text { General } \\
\text { Electrics } \\
\text { RT3000 }\end{array}$ & Linear & $5 \mathrm{MHz}$ & 12 & $\begin{array}{l}\text { No deviations }(58 \%) \\
\text { Hypoechoic lesions }(42 \%) \\
\text { Heterogeneous echogenicity }(42 \%) \\
\text { Muslce fibers structure } \\
\text { disorganization }(42 \%) \\
\text { Hyperechoic lesion }(17 \%)\end{array}$ & $1516-889000 \mathrm{U} / 1$ \\
\hline $\begin{array}{l}\text { Reimers } \\
1992[12]\end{array}$ & NI & NI & $3.75 \mathrm{MHz}$ & 3 & $\begin{array}{l}\text { Higher echogenicity }(33 \%) \\
\text { Hypoechoic lesion }(33 \%) \\
\text { No deviations }(33 \%)\end{array}$ & $7800-17500 \mathrm{U} / 1$ \\
\hline $\begin{array}{l}\text { Steeds } \\
1999[13]\end{array}$ & $\begin{array}{l}\text { Toshiba } \\
\text { sonolayer } \\
\text { SSA-270a }\end{array}$ & NI & $7.5 \mathrm{MHz}$ & 1 & $\begin{array}{l}\text { Lower echogenicity } \\
\text { Heterogeneous echogenicity } \\
\text { Hyperechoic lesions } \\
\text { Traits of edema } \\
\text { Muslce fibers structure disorganization }\end{array}$ & $78000 \mathrm{U} / 1$ \\
\hline $\begin{array}{l}\text { Chiu } \\
2008 \text { [14] }\end{array}$ & $\begin{array}{l}\text { Phillips } \\
\text { HDI-5000 }\end{array}$ & Linear & $5-12 \mathrm{MHz}$ & 1 & $\begin{array}{l}\text { Lower echogenicity } \\
\text { Muslce fibers structure disorganization } \\
\text { Thickening of the muscle }\end{array}$ & $1314 \mathrm{U} / 1$ \\
\hline $\begin{array}{l}\text { Shah } \\
2008 \text { [15] }\end{array}$ & NI & NI & NI & 1 & $\begin{array}{l}\text { Heterogeneous echogenicity } \\
\text { Hypoechoic lesions } \\
\text { Hyperechoic lesions } \\
\text { Thickening of the muscle } \\
\text { Traits of edema }\end{array}$ & $106645 \mathrm{U} / 1$ \\
\hline $\begin{array}{l}\mathrm{Su} \\
2009 \text { [16] }\end{array}$ & $\begin{array}{l}\text { Phillips } \\
\text { HD-11 }\end{array}$ & NI & 8-12 MHz & $\begin{array}{l}50 \text { with } \\
\text { compartment } \\
\text { syndrome } \\
18 \text { without } \\
\text { compartment } \\
\text { syndrome }\end{array}$ & $\begin{array}{l}\text { Without compartment syndrome } \\
\text { Traits of edema }(90 \%) \\
\text { Thickening of the muscle }(88 \%) \\
\text { Ground glass opacity }(88 \%) \\
\text { Anechoic areas }(80 \%) \\
\text { With compartment syndrome } \\
\text { Traits of edema }(89 \%) \\
\text { Thickening of the muscle }(100 \%) \\
\text { Ground glass opacity }(89 \%) \\
\text { Anechoic areas }(83 \%) \\
\text { Arched protrusion and displacement of } \\
\text { fascia above the lesions }(78 \%)\end{array}$ & $\begin{array}{l}\text { With compartment } \\
\text { syndrome } \\
986 \text { - } 20466 \mathrm{U} / 1 \\
\text { Without compart- } \\
\text { ment syndrome } \\
1385-40568 \mathrm{U} / 1\end{array}$ \\
\hline $\begin{array}{l}\text { Pierson } \\
2014 \text { [17] }\end{array}$ & $\begin{array}{l}\text { GE } \\
\text { LOGIQ e }\end{array}$ & NI & 8-13 MHz & 1 & $\begin{array}{l}\text { Heterogeneous echogenicity } \\
\text { Hyperechoic lesions } \\
\text { Ground glass opacity } \\
\text { Hypoechoic lesions }\end{array}$ & $31950 \mathrm{U} / 1$ \\
\hline $\begin{array}{l}\text { Carrillo- } \\
\text { Esper } \\
2016[18]\end{array}$ & $\begin{array}{l}\text { Phillips } \\
\text { Sparq }\end{array}$ & Linear & 5-10 MHz & 1 & $\begin{array}{l}\text { Heterogeneous echogenicity } \\
\text { Hypoechoic lesions } \\
\text { Thickening of the fascia } \\
\text { Ground glass opacity } \\
\text { Anechoic areas }\end{array}$ & $>41000 \mathrm{U} / 1$ \\
\hline $\begin{array}{l}\text { Nassar } \\
2016 \text { [19] }\end{array}$ & NI & NI & NI & 1 & $\begin{array}{l}\text { Heterogeneous echogenicity } \\
\text { Hypoechoic lesions } \\
\text { Hyperechoic lesions } \\
\text { Muslce fibers structure disorganization } \\
\text { Anechoic areas }\end{array}$ & $83000 \mathrm{U} / 1$ \\
\hline $\begin{array}{l}\text { Boyle } \\
2017[20]\end{array}$ & $\mathrm{NI}$ & Linear & $5-12 \mathrm{MHz}$ & 2 & $\begin{array}{l}\text { Higher echogenicity }(100 \%) \\
\text { Ground glass opacity }(100 \%) \\
\text { Hypoechoic lesions }(100 \%) \\
\text { Heterogeneous echogenicity }(100 \%)\end{array}$ & $15000-38000 \mathrm{U} / 1$ \\
\hline
\end{tabular}

$\mathrm{NI}$ - no information; $\mathrm{N}$ - number of cases; $\mathrm{CK}$ - creatine kinase (plasma concentration or range if more than one case); *percentage of cases in which were found, if more than one case was described 
Table II. Deviations described in analyzed publications

\begin{tabular}{|c|c|c|}
\hline Ultrasound findings & $\begin{array}{l}\text { N }(\%) / \\
\text { n }(\%)\end{array}$ & $\begin{array}{l}\text { Number of } \\
\text { papers } \\
\text { (all / published } \\
\text { between } \\
2008-2017 \text { ) }\end{array}$ \\
\hline Thickening of the muscle & $65(70) / 65(87)$ & $4 / 4$ \\
\hline Ground glass opacity & $64(69) / 64(85)$ & $4 / 4$ \\
\hline Traits of edema & $63(68) / 62(83)$ & $3 / 2$ \\
\hline Anechoic areas & $57(61) / 57(76)$ & $3 / 3$ \\
\hline $\begin{array}{l}\text { Arched protrusion and } \\
\text { displacement of fascia } \\
\text { above the lesions }\end{array}$ & $14(15) / 14(19)$ & $1 / 1$ \\
\hline $\begin{array}{l}\text { Hipoechoic lesion or } \\
\text { lesions }\end{array}$ & $14(15) / 6(8)$ & $9 / 5$ \\
\hline $\begin{array}{l}\text { Heterogeneous } \\
\text { echogenicity }\end{array}$ & $12(13) / 6(8)$ & $7 / 5$ \\
\hline $\begin{array}{l}\text { Muslce fibers structure } \\
\text { disorganization }\end{array}$ & $8(9) / 2(3)$ & $4 / 2$ \\
\hline $\begin{array}{l}\text { Hyperechoic lesion or } \\
\text { lesions }\end{array}$ & $6(6) / 3(4)$ & $5 / 3$ \\
\hline Higher echogenicity & $4(4) / 3(4)$ & $3 / 2$ \\
\hline Lower echogenicity & $2(2) / 1(1)$ & $2 / 1$ \\
\hline $\begin{array}{l}\text { Hyperechoic } \\
\text { intercalation inside } \\
\text { hypoechoic lesion }\end{array}$ & $1(1) / 0(0)$ & $1 / 0$ \\
\hline Thickening of the fascia & $1(1) / 1(1)$ & $1 / 1$ \\
\hline No pathological findings & $8(9) / 0(0)$ & $2 / 0$ \\
\hline
\end{tabular}

$\mathrm{N}$ - number of cases with a specific ultrasound finding from all analyzed papers; n- number of cases with a specific ultrasound finding from the papers published between 2008-2017

findings reported. The rest of the findings were described in the remainder of both publications and cases.

\section{Discussion}

The history of the diagnosis of rhabdomyolysis using US began in early eighties, and since then only scarce amount of research, mainly case reports, was made. Carrying out a credible meta-analysis of that data and finding precise US appearance of rhabdomyolysis is impossible, based on several reasons. The varied etiology of muscle lysis may give different macroscopic changes and possibly different US appearance. Drawing definitive conclusions from such limited data may in fact make the diagnosis harder, as images seen by a clinician may be entirely different from the guidelines based on an incomplete information. Thus, there is a need for studies concentrated on US appearance of rhabdomyolyses of similar etiology. Next, but nonetheless an important factor is the technology which plays a vital role in US. Since the early eighties there has been a rapid growth of quality and frequency of transducers, imaging software and hardware, changing both how and what can be seen, and allowing for lesions smaller than before and hidden under artifacts to be assessed. Moreover, the introduction of harmonics and cross-beam technology additionally helped with the removal of various artifacts interfering with the examination, and made the image clearer. Because of that progress, images acquired before the introduction of newer technologies may not help with the diagnosis nowadays, as appearance after enhancement may be vastly different. These were our reasons for comparing data about findings described in different time ranges. Lastly, the method of examination may also influence the image seen on the monitor, and since there were no specified techniques for every published study, it may have caused additional differences in the findings. Because of these reasons, we decided to perform only a systematic review, to serve as an aid and compiled data source for further research on the subject of usage of ultrasound in the diagnosis of rhabdomyolysis. Additionally, the images we acquired during examination of a patient with confirmed rhabdomyolysis (fig 2), after comparison with table II made in this study, has shown us that the findings were consistent with those found in previously described cases of the rhabdomyolysis, and that it is with a high probability site of muscle lysis. The tables presented in this study may be used by both physicians and other pro-

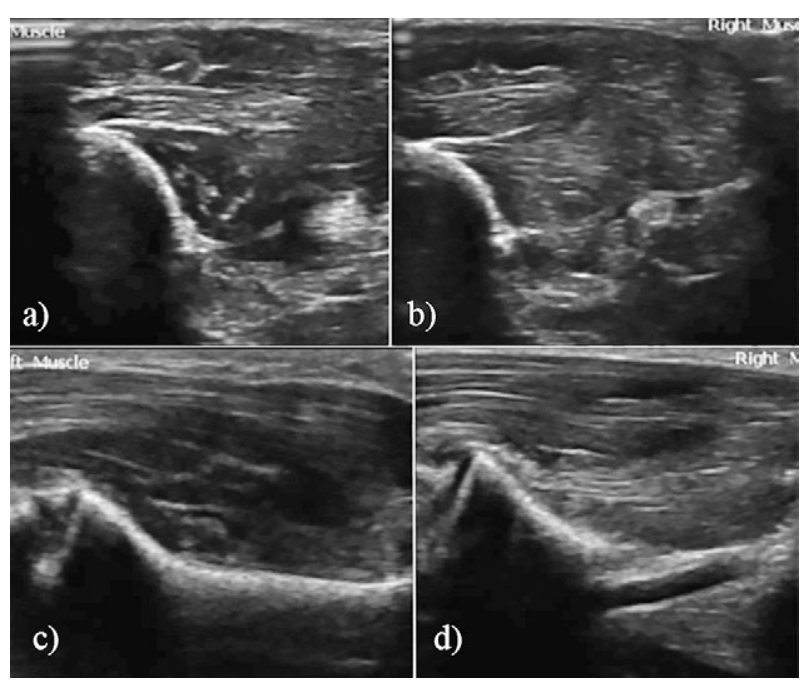

Fig 2. Transverse (a and b) and longitudinal (c and d) sections through left (a and c) and right (b and d) thenar of a 31-year old male poisoned with unknown psychoactive substances and CK plasma level measuring up to $5600 \mathrm{U} / \mathrm{l}$. Left thenar presented redness, tenderness and swelling, probably caused by injury during psychoactive agitation. Visible decrease of muscle echogenicity, presence of hypoechoic lesions and small anechoic areas (a and c), compared to the normal muscle appearance (b and d). Image acquired with Phillips SPARQ using $10 \mathrm{MHz}$ linear transducer. 
fessionals such as physiotherapists researching the subject of the US appearance of rhabdomyolysis as a useful data source for comparison of what they acquired with what was acquired previously.

\section{Conclusions}

Rhabdomyolysis seems to have its own US appearance, mostly in a form of muscle thickening, ground glass opacity, traits of edema, anechoic areas and various less often reported lesions. Due to the small number of published cases the typical aspect of rhabdomyolysis is not clear and needs further research for clarification.

\section{Conflict of interest: none}

\section{References}

1. Zutt R, van der Kooi AJ, Linthorst GE, Wanders RJ, de Visser M. Rhabdomyolysis: Review of the literature. Neuromuscul Disord 2014;24:651-659.

2. Prygiel J, Potulska-Chromik A, Kostera-Pruszczyk A. Rhabdomyolysis in clinical practice. Child Neurol2017;26:55-61.

3. Al-Ismaili Z, Piccioni M, Zappitelli M. Rhabdomyolysis: pathogenesis of renal injury and management. Pediatr Nephrol 2011;26:1781-1788.

4. Liu ZZ, Mathia S, Pahlitzsch T, et al. Myoglobin facilitates angiotensin II-induced constriction of renal afferent arterioles. Am J Physiol Renal Physiol 2017;312:F908-F916.

5. Zuk A, Bonventre JV. Acute Kidney Injury. Annu Rev Med 201667:293-307.

6. Patel RB, Tannenbaum S, Viana-Tejedor A, et al. Serum potassium levels, cardiac arrhythmias, and mortality following non-ST-elevation myocardial infarction or unstable angina: insights from MERLIN-TIMI 36. Eur Heart J Acute Cardiovasc Care 2017;6:18-25.

7. Chavez LO, Leon M, Einav S, Varon J. Beyond muscle destruction: a systematic review of rhabdomyolysis for clinical practice. Crit Care 2016;20:135.
8. Long S, Garrett J, Bhargava P, Aguilar G, Simoncini A, Sangster G. Multimodality imaging findings in rhabdomyolysis and a brief review of differential diagnoses. Emerg Radiol 20177;24:387-392.

9. Kaplan GN. Ultrasonic apperance of rhabdomyolysis. AJR Am J Roentgenol 1980;134:375-377.

10. Fornage BD, Nerot C. Sonographic diagnosis of rhabdomyolysis. J Clin Ultrasound 1986;14:389-392.

11. Lamminen AE, Hekali PE, Tiula E, Suramo I, Korhola OA. Acute rhabdomyolysis: evaluation with magnetic resonance imaging compared with computed tomography and ultrasonography. Br J Radiol 1989;62:326330.

12. Reimers CD, Haider M, Mehltretter G, Kääb S, Wunderer B, Pongratz DE. Rectus-abdominis-Syndrom. Dtsch Med Wochenschr 1992;117:1474-1478.

13. Steeds RP, Alexander PJ, Muthusamy R, Bradley M. Sonography in the Diagnosis of rhabdomyolysis. J Clin Ultrasound 1999;27:531-533.

14. Chiu YN, Wang TG, Hsu CY, et al. Sonographic Diagnosis of Rhabdomyolysis. J Med Ultrasound 2008;16:158-162.

15. Shah HV, Irvine GH, Bradley M. Rhabdomyolysis of the masseter muscle: Case report. Br J Oral Maxillofac Surg 2008;46:138-140.

16. Su BH, Qiu L, Fu P, Luo Y, Tao Y, Peng YL. Ultrasonic appearance of rhabdomyolysis in patients with crush injury in the Wenchuan earthquake. Chin Med J (Engl) 2009;122:1872-1876.

17. Pierson EH, Bantum BM, Schaefer MP. Exertional Rhabdomyolysis of the Elbow Flexor Muscles From Weight Lifting. PM R 2014;6:556-559.

18. Carrillo-Esper R, Galván-Talamantes Y, Meza-Ayala CM, Cruz-Santana JA, Bonilla-Reséndiz LI. Ultrasound findings in rhabdomyolysis. Cir Cir 2016;84:518-522.

19. Nassar A, Talbot R, Grant A, Derr C. Rapid Diagnosis of Rhabdomyolysis with Point-of-Care Ultrasound. West J Emerg Med 2016;17:801-804.

20. Boyle J, Marks P, Read J. Rectus Abdominis Rhabdomyolysis: Report of 2 Cases. J Ultrasound Med 2017;36:21652171. 